\title{
Epicardial myocardial strain abnormalities may identify the earliest stages of arrhythmogenic cardiomyopathy
}

Patricia Réant ${ }^{\star 1,2}$, Arnaud D. Hauer ${ }^{1,3}$, Silvia Castelletti ${ }^{1}$, Antonis Pantazis ${ }^{1}$; Stefania Rosmini1'; Mun Hong Cheang ${ }^{1}$; Jérôme Peyrou²; Maite Tomé-Esteban ${ }^{1}$; Petros Syrris $^{1}$; Stéphane Lafitte ${ }^{2}$; James C. Moon ${ }^{1}$; William J. McKenna ${ }^{1}$

${ }^{1}$ Inherited Cardiac Disease Unit and Division of Cardiovascular Imaging, The Heart Hospital; Institute of Cardiovascular Science, University College London, London, United Kingdom;

2 University of Bordeaux, CHU de Bordeaux, CIC1401 (Pessac), Bordeaux, France;

${ }^{3}$ Haga Teaching Hospital, The Hague, The Netherlands.

Brief title: Multilayer strain in AC mutation carriers

Word count: 3999 words

${ }^{*}$ Corresponding author:

Dr Patricia Réant

Hôpital Cardiologique Haut-Lévêque, 1 avenue de Magellan, 33604 Pessac Cedex, France. Tel: +33 (0)5 57656430, Fax: +33 (0)557656012

patricia.reant@chu-bordeaux.fr 


\section{Abstract}

Purpose: The aim of this cohort study was to evaluate the value of echocardiographic multilayer strain analysis in the identification of arrhythmogenic cardiomyopathy $(A C)$ in its earliest stages in which sudden cardiac death can occurs.

Methods and Results: Twenty seven asymptomatic relatives of $A C$ probands (mean age $39.6 \pm 19.5$ years, $37 \%$ male) with a desmosomal pathogenic mutation but no additional criteria for AC (group II) were compared to age and sex-matched healthy controls (group I). In addition, 70 patients harboring a pathogenic desmosomal mutation with "definitive" diagnosis of AC (group IV), and 19 subjects with "borderline" diagnosis (group III) were also studied. A standard echocardiographic evaluation plus left (LV) and right ventricular (RV) global and regional transmural, endocardial, and epicardial longitudinal strain (LS) analysis, was performed. In group II, while LV ejection fraction, fractional shortening, and S' were not significantly reduced compared to controls, transmural global LS was significantly reduced to $19.3 \pm 1.8 \%$ in group II vs. $20.9 \pm 1.1 \%$ in controls $(p=0.0003)$. Compared to controls, group II presented significant $(p<0.05)$ regional LS decrease in the basal infero-lateral, antero-lateral, latero-apical, infero-septal, and septo-apical segments. Moreover, LS of the latero-apical and the basal antero-lateral segments was significantly altered in the epicardium $(p<0.05)$ but not significantly in the endocardium.

Conclusions: Global and regional LV LS analysis allows detection of AC in an early or non-diagnostic stage of the disease. Moreover, epicardial LS analysis allows the detection of abnormalities earlier than endocardial LS. 
Key words: echocardiography; speckle tracking; myocardial strain; arrhythmogenic cardiomyopathy; cardiac imaging

\section{Abbreviation List}

$\mathrm{AC}=$ arrhythmogenic cardiomyopathy

$\mathrm{CMR}=$ cardiovascular magnetic resonance

$E F=$ ejection fraction

$L V=$ left ventricle

LGE = late gadolinium enhancement

LS = longitudinal strain

$\mathrm{ROC}=$ receiver operating characteristics

$\mathrm{RV}=$ right ventricle

TFC $=$ Task Force Criteria 


\section{Introduction}

Arrhythmogenic cardiomyopathy $(\mathrm{AC})$ is a genetic disease of the desmosome which is characterized by ventricular arrhythmias and myocardial dysfunction. Often both right ventricular (RV) and left ventricular (LV) myocardium are involved [1].

In AC, sudden cardiac death often occurs in the concealed phase in asymptomatic subjects when no or only subtle signs of the disease are observed [2]. The diagnosis is currently made on the presence of major and minor Task Force Criteria (TFC) that include structural, functional, anatomical, histological, electrocardiographic, arrhythmic, and genetic factors. Current guidelines recommend that all patient's first degree relatives with AC undergo ECG, echocardiography, and screening of the pathogenic gene mutation when identified [3]. Since sudden death may occur in the absence of current TFC there is a strong need to develop novel diagnostic methods to identify the disease.

Speckle-tracking strain analysis by echocardiography is well recognized now to allow easily early detection of LV longitudinal contractility abnormalities while ejection fraction $(E F)$ is still preserved in various pathologies (e.g hypertrophic cardiomyopathy, cardiac amyloidosis, severe asymptomatic aortic valve stenosis)[4$6]$.

A recent development of this tool called "multilayer strain analysis" allows analyzing separately both the endocardial and the epicardial half part of the myocardial wall [79]. The aim of this cohort study was to evaluate the additional value of endo- and epicardial speckle-tracking deformation analysis to detect early subclinical LV and $\mathrm{RV}$ function abnormalities in asymptomatic carriers of pathogenic AC desmosomal mutations. 


\section{Methods}

This was an observational single-centre cohort study performed in the specialized Inherited Heart Disease Unit at The Heart Hospital, London, United Kingdom. We studied the cohort of AC attending from August 2009 to May 2014. All consecutive patients were eligible for the study.

The study inclusion criteria were patients aged $\geq 12$ years with diagnosis of $A C$ based on 2010 TFC, or their relatives who carried the same pathogenic desmosomal AC mutation but did not fulfill diagnostic criteria [3].

Exclusion criteria were as follows: (1) permanent or persistent atrial fibrillation at the study visit; (2) poor echocardiographic image quality (inability to perform strain analysis due to poor echo window (more than 3 LV segments not correctly visualized or, non accurate tracking or reverberation artefacts); (3) concomitant pathologies known to impair longitudinal contraction (e.g. diabetes, myocardial infarction, hypertension).

Demographic characteristics were collected from the hospital records at the time of echocardiography. Cardiovascular magnetic resonance (CMR) analysis of late gadolinium enhancements (LGE) was analyzed when CMR was performed within less than 12 months compared to the reference echocardiography.

Patients were diagnosed with AC based on fulfillment of the TFC of the current guidelines [3]. All individuals in groups II, III, and IV carried at least one pathogenic desmosomal mutation. Group IV consisted of patients with "definitive" AC diagnosis according to TFC 2010 (2 major criteria or 1 major and 2 minor criteria or 4 minor criteria from different categories). Group III consisted of patients with 
"borderline" AC diagnosis according to TFC 2010 (1 major and 1 minor criterion or 3 minor criteria from different categories). Group II consisted of relatives of AC patients that only carried at least one pathogenic desmosomal mutation consequently fulfilling the definition of a "possible" diagnosis of AC (=1 major criterion). Healthy volunteers were recruited as controls (group I). All were asymptomatic and lacked family history of premature cardiovascular disease. No one was on cardiac medication. All participants gave informed consent conforming to the Declaration of Helsinki.

The echocardiography protocol was based on standardized acquisitions in all patients attending the clinic [10]. Resting two-dimensional echocardiography was performed according to American Society of Echocardiography guidelines [10,11], with a Vivid 7 or E9 machine equipped with a M3S transducer (General Electric Medical System $\AA$, Horten, Norway). Recordings in standardized views were acquired in two-dimensional, M-mode, pulsed Doppler, continuous Doppler, color Doppler, and pulsed tissue Doppler imaging modalities, and digitally stored for subsequent off-line analysis on a dedicated workstation (Echopac® software version BT11.3 (General Electric Medical System ${ }^{\circledR}$, Horten, Norway). One independent and experienced observer (P.R.), blinded to the patient's history, analyzed all the echocardiograms, applying standard measurements according to European Association of Echocardiography/American Society of Echocardiography guidelines [10,11]. LV volumes and LVEF were calculated using biplane Simpson's rule [10]. Biplane maximal left atrial volume was calculated using the area-length method, and then was indexed to body surface area. LV filling pressures were estimated using pulsed Doppler mitral inflow and the ratio of peak E wave over E' on tissue Doppler imaging at the lateral side of the mitral annulus. RV measurements were performed as previously described $[12,13]$. RV end-diastolic and end-systolic areas were used 
to calculate the RV fraction of area change (in \%) using a modified 4-chamber view focused on the RV. RV outflow tract diameter was measured in parasternal short axis view. The presence of RV akinesia, dyskinesia, or aneurysm was qualitatively appreciated. Tricuspid annular plane systolic excursion was measured as well as S' peak longitudinal systolic velocity by tissue Doppler imaging, at the basal lateral RV free wall. Pulmonary artery systolic pressure was measured according to the guidelines [13]. Left ventricular longitudinal strain (LS) was quantified in the three apical views using the two-dimensional speckle-tracking echocardiographic method $[4,14]$. The frame rate of the recordings was between 45 and 75 ips. GLS was presented in magnitude throughout the manuscript. Transmural end-systolic peak values of LS were recorded in a 17 segments model and global LS was calculated as the mean of the 17 segments. The region of interest was manually set to ensure an accurate covering of the myocardial wall. The software automatically split the LV wall region of interest in two equal half parts: endocardial, and epicardial given endocardial and epicardial LS for each of the 17 segments. For the RV, the same analysis was performed for the 3 lateral free wall segments (using the 4 chamber view; basal, mid and apical segments) when the image was considered of sufficient quality to allow accurate tracking. RV strain analysis was considered accurate and performed when wall thickness was totally visualized from endocardium to epicardium.

CMR scan with LGE was performed when clinically indicated. Standard clinical scans (localizers, 3 long-axis views, black and white blood images, full LV short-axis stack) were performed using a 1.5-T magnet (Avanto, Siemens Medical Solutions, Erlangen, Germany). CMR short-axis volumetric studies [15] were acquired from retrospectively gated, breath-held, balanced, steady-state free- 
precession cines (slice thickness, $7.0 \mathrm{~mm}$; interslice gap, $3.0 \mathrm{~mm}$; flip angle, $60^{\circ}-$ $80^{\circ}$; repetition time, $3.0 \mathrm{~ms}$; echo time, $1.33 \mathrm{~ms}$; field of view read typically, $380 \mathrm{~mm}$; phase resolution, $75 \%$; typical acquired voxel size, $1.5 \times 1.7 \mathrm{~mm}$; lines per segment). Breath-held, LGE images acquired through an inversion recovery turbo fast lowangle shot sequence were obtained 7 to 15 minutes after injection of $0.1 \mathrm{mmol} / \mathrm{kg}$ gadolinium-diethylenetriamine penta-acetic acid. For the purpose of this study, the presence of LGE and the structure of the LV were evaluated retrospectively by cardiologists experienced in CMR (S.C. and J.C.M.) on CMR scans which were performed within 12 months of the echocardiography. For each of the 17 segments, endocardial and epicardial parts of the myocardial wall were coded according to presence or absence (1 or 0 ) of LGE.

All statistical analyses were performed using SPSS® (Version 17.0, SPSS Inc., Chicago, IL, USA). Continuous variables were expressed as mean $\pm S D$ or median (IQR), and categorical variables as frequencies and percentages. Comparison between groups I and II continuous variables were performed using an unpaired student $t$ test. For comparison between the 4 groups, an Anova one-way test was performed. Receiver Operating Characteristics curve was performed to assess the relation between LS and presence of LGE, and to determine optimal cutoff value of LV LS to predict presence of LGE. Our methods comply with the STROBE statement [16]. $P$ values were two-sided, and a $p$ value $\leq 0.05$ was considered statistically significant.

To assess intraobserver variability, data from 16 subjects were analyzed twice offline by the same operator (P.R.), with at least 1 week-interval between the two analyses. A second observer (A.H.) blinded to the results of the preceding investigations similarly performed the 16 analyses in order to assess interobserver 
variability. Variability was expressed as percentage. Percentage of variability was calculated as the absolute difference divided by the average of the two measurements of the same dataset. This was performed for global and regional analysis of both the LV and RV, on a transmural basis as well as for endocardial strain and epicardial strain.

\section{Results}

Among 131 mutation carrier patients (2006-2012), 2 were excluded because of permanent atrial fibrillation, and 13 were excluded due to inability to record LV strain analysis as a consequence of insufficient image quality.

Accordingly, data from 142 subjects were finally analyzed: 70 patients with "definitive" diagnosis of AC (group IV), 19 patients with "borderline" diagnosis (group III), 27 asymptomatic carriers of a pathogenic desmosomal mutation with consequently "possible" diagnosis of AC (group II, mean age of $39.6 \pm 19.5$ years, $37 \%$ male), and 26 healthy controls (group I, mean age $38.7 \pm 11.4$ years, $38 \%$ male).

The demographics, clinical and main echocardiographic characteristics of the population are presented in Table 1. Although normal in some cases, mean of all RV systolic function parameters were significantly altered in groups III and IV compared to controls (group I) but only tricuspid annular plane systolic excursion, S' by tissue Doppler imaging, and global RV strain were significantly altered in group II compared to controls (transmural RV LS was $26.8 \pm 5.1 \%$ in group II vs. $31.0 \pm 4.2 \%$ in controls, $\mathrm{p}=0.005)$. Table 2 shows results at RV basal, mid and apical level in the four groups. 
The LVEF was relatively preserved in all TFC groups while LV GLS was significantly impaired in group II compared to controls $(19.3 \pm 1.8 \%$ vs. $20.9 \pm 1.1 \%$, $\mathrm{p}=0.0003)$ (Table 1).

Feasibility of strain analysis on the RV was $75 \%$ (319/426 segments correctly tracked), and $94 \%$ on the LV (2271/2414 segments correctly tracked).

Left ventricular regional strain analysis (Figures 1, 2, 3) showed significant abnormalities located particularly in the infero-lateral, antero-lateral, and infero-septal walls in group II compared to controls $(p<0.05)$. However, LS of the latero-apical and the basal antero-lateral segments were significantly altered only in the epicardium (Figure 3) but not in the endocardium (Figure 2). In this study, if we consider a value of $<17 \%$ for abnormal LV regional longitudinal strain [4], 18 (67\%) over 27 desmosomal-gene mutation carriers had at least 3 abnormal regional strain values (vs $19 \%$ of the controls).

Table 3 depicts the relatively good intra- and inter-observer reproducibilities for global LV LS (variability between $3.1 \%$ to $6.1 \%$ ) and RV strain analyses (between $6.1 \%$ and $11.9 \%$ ), transmural as well as endocardial and epicardial analyses. Variability was relatively higher for regional analysis (between $7.8 \%$ and $11.5 \%$ for mean intraobserver analysis, and between $9.7 \%$ and $13.0 \%$ for interobserver analysis).

CMR scans performed at $<12$ months of the echocardiography was available for retrospective analysis for 28 AC patients (19 of the group IV, 3 of the group III, and 6 of the group II). This corresponds to 578 half LV segments analyzed. Figure 4 displays the receiver operating characteristics (ROC) curve analysis of regional LS 
analysis to predict presence of LGE. AUC was $0.69(95 \% \mathrm{Cl}=0.63-0.75)$ with the best cut-off value of LS $\leq 17.5 \%$ giving a sensitivity of $72 \%$, and specificity of $57 \%$.

\section{Discussion}

This study is the first to have investigated regional endo- vs. epicardial longitudinal LS analysis by speckle-tracking echocardiography in both LV and RV in AC patients and in desmosomal mutation carriers compared to healthy controls. This analysis highlights LV longitudinal regional epicardial strain alteration to be more sensitive than endocardial strain in identifying early LV contraction abnormalities. Epicardial strain was particularly altered in the latero-apical and in the basal antero-lateral segments in $A C$ relatives who carry a pathogenic desmosomal mutation, but did not show other signs of $A C$; RV longitudinal strain was also impaired in these patients, particularly in the mid lateral segment.

Arrhythmogenic cardiomyopathy is a diffuse and progressive heart muscle disease predominantly involving the free wall of the $\mathrm{RV}$ in which the myocardium is replaced by fatty and fibro-fatty tissue. Although the disease is more often recognized in the $\mathrm{RV}$ presenting structural and functional abnormalities, the $L V$ is also affected in many cases $[1,17]$. In one autopsy study, LV involvement was found in up to $76 \%$ of 42 subjects who died suddenly or were explanted with a pathological diagnosis of $A C[1]$.

The presence of a pathogenic desmosomal mutation detected in a first degree relative of a patient with $A C$ is considered in itself as one major criterion for $A C$. If imaging modalities (echocardiography or CMR) detect one minor criterion, the 
diagnosis is "borderline". If one additional minor or major criterion is identified, the diagnosis of $A C$ is "definitive" [3]. CMR is a valuable imaging technique for detecting abnormalities in AC: abnormal RV free wall morphology (focal aneurysms), wall motion abnormalities, global ventricular dilatation, presence of fatty infiltration that can be suppressed in fat suppression sequences, or myocardial fibrosis (LGE) which often co-exists in the fat-infiltrated RV myocardium [18-20]. The presence of LGE is also a predictor of inducible ventricular tachycardia on electrophysiological studies [18]. However, for either screening a large group of subjects or for the detection of early disease, a CMR examination may not be the technique of choice. Detection of $\mathrm{RV}$ wall motion abnormalities by echocardiography, if shown to be sufficiently sensitive and specific, could be a more appropriate imaging approach because of its availability and lower costs. According to 2010 revised TFC [3], a minor criterion of AC is present if echocardiography detect regional RV akinesia, dyskinesia, or aneurysm, and 1 of the following (end-diastolic measurements):

- parasternal long axis RV outflow tract diameter $\geq 29 \mathrm{~mm}$ to $<32 \mathrm{~mm}\left(\geq 16 \mathrm{~mm} / \mathrm{m}^{2}\right.$ to $\left.<19 \mathrm{~mm} / \mathrm{m}^{2}\right)$ [major criteria if $\geq 32 \mathrm{~mm}\left(\geq 19 \mathrm{~mm} / \mathrm{m}^{2}\right)$ ]

- parasternal short axis RV outflow tract diameter $\geq 32 \mathrm{~mm}$ to $<36 \mathrm{~mm}\left(\geq 18 \mathrm{~mm} / \mathrm{m}^{2}\right.$ to $\left.<21 \mathrm{~mm} / \mathrm{m}^{2}\right)$ [major criteria if $\geq 36 \mathrm{~mm}\left(\geq 21 \mathrm{~mm} / \mathrm{m}^{2}\right)$ ]

- or RV fractional area change $>33 \%$ to $\leq 40 \%$ [major criteria if $\leq 33 \%$ ]

However, at early stages of the disease visual detection of wall motion abnormalities is challenging regardless of the technique applied (echo or CMR). As longitudinal dysfunction precedes wall motion abnormalities and EF impairment in various cardiomyopathies, if wall motion abnormalities are absent, evaluation of longitudinal function could be very helpful and more sensitive [21]. Tissue Doppler imaging has 
been shown to enable quantitative assessment of RV function and the detection of AC [22]. However, this technique is subject to some limitations such as Doppler angle dependency particularly at mid and apical segments.

Strain analysis has previously demonstrated the capability to detect both early LV and RV LS abnormalities in AC mutation carriers without $\mathrm{RV}$ wall motion abnormalities. Teske et al showed a high feasibility of speckle-tracking echocardiographic measurements in AC patients [23,24]. Fourteen asymptomatic first-degree relatives of $A C$ probands with a pathogenic plakophilin-2 mutation were compared to healthy controls [24]. RV dimensions in the AC relative group were similar to those in controls and global systolic parameters were moderately reduced (tricuspid annular plane systolic excursion was altered significantly but not RV fractional area change). Doppler tissue imaging and speckle-tracking strain (and strain rate) values were reduced in the $A C$ mutation carriers group in the basal and mid RV segments compared with controls $(p<0.001)$. In this study, a cut-off of $18 \%$ was used to define abnormal RV strain. According to recent international guidelines, normal values for RV strain are $29.0 \pm 4.5 \%$ [25] and $28.3 \pm 8.2 \%$ in a recent study [26], and strain of the RV free wall is considered abnormal when $<20.0 \%$ [25]. In another recent study, 19 male first degree relatives of patients with definitive diagnosis of $A C$ were compared to 22 healthy volunteers [27]. Speckle-tracking was feasible for both ventricles in AC patients, relatives and controls. However, LS was analyzed only for two LV segments (basal and mid level segments of the lateral wall), and four RV segments (basal and mid level segments of the lateral RV free wall, and basal and mid level segments of the septal wall). Only basal septum LS was significantly lower in relatives compared to controls $(15.8 \%$ vs $17.8 \%, p=0.025)$ [27]. Our study investigated LV regional and global strain abnormalities in a 17 
segments model while only 2-4 LV segments were analyzed in this previous cited study. In addition, we analyzed LS transmurally with specific endocardial and epicardial measurements using dedicated software. The ability to differentiate here myocardial layers (endocardium and epicardium parts) is particularly relevant as it is well recognized that disease involvement frequently begins in the epicardium with the endocardial involvement developing at a later stage [20]. In our study, while LVEF, fractional shortening, and S' by tissue Doppler imaging were not significantly reduced compared to controls, transmural global LV LS was significantly reduced in desmosomal mutation carriers compared to controls $(p=0.0003)$. Compared to controls, group II presented significant regional LS alterations particularly in the infero-lateral, antero-lateral, and infero-septal walls $(p<0.05)$. In addition, compared to controls, LS of the latero-apical and the basal antero-lateral segments were significantly altered only in the epicardium while endocardial LS was not, consistent with early detection of disease.

The strength of this single centre large cohort study is it systematically investigated LV regional and global myocardial strain abnormalities in a 17 segments model, and then separating epicardial and edocardial wall parts. Follow-up will be useful to confirm that LS (epicardial \pm endocardial strain) regional abnormalities precede or predict the subsequent development of overt stages of the disease. Consistent with this hypothesis is the finding that ROC curves demonstrated that LS $>17.5 \%$ predicted the presence of LGE. However, in clinical use, it is important to keep in mind that several factors such as ethnicity, age, diabetes, myocardial ischemia, and hypertension might reduce LS and should be taken in account for careful interpretation of the data. There are also some limitations. We acknowledge that the choice of a LS cut-off value was based on the little data available. Although 
LS measurements have previously been described as concordant when compared to another vendor, the use of cut-off values has not been tested when using different devices [28].

In clinical practice, global and regional LV strain with endocardial and epicardial analysis could be performed easily at the bedside in less than 3 min, with good intra- and interobserver reproducibility. Larger and multicentre studies will be needed to confirm these findings and evaluate the clinical diagnostic utility of LV strain measurements, as well as their predictive value for ventricular arrhythmia and heart failure outcomes.

\section{Conclusions}

Global and regional LV LS analysis allows detection of $A C$ at a very early stage in mutation carriers when other parameters of LV systolic function are apparently still normal. Moreover, epicardial LS analysis allows a better detection of abnormalities earlier than endocardial LS. 
Conflict of interest: none declared.

\section{Sources of Funding and Acknowledgements}

This work was undertaken at University College London Hospitals/University College London, which receives a proportion of funding from the Department of Health's NIHR Biomedical Research Centre funding scheme. Professors JCM and WJM are funded by the Higher Education Funding Council for England.

Dr PR was supported by the Fédération Francaise de Cardiologie.

Dr AH was supported by the Leiden University Medical Center.

Dr SC was funded by the 2014 ESC research grant.

Professor PS was supported by NIHR Biomedical Research Centre at UCL/UCLH.

We thank Mrs Shaughan Dickie and Mrs Sarah Anderson for their help. 


\section{References}

1. Corrado D, Basso C, Thiene G, McKenna WJ, Davies MJ, Fontaliran F, Nava A, Silvestri F, Blomstrom-Lundqvist C, Wlodarska EK, Fontaine G, Camerini F (1997) Spectrum of clinicopathologic manifestations of arrhythmogenic right ventricular cardiomyopathy/dysplasia: a multicenter study. J Am Coll Cardiol $30: 1512-20$

2. Thiene G, Nava A, Corrado D, Rossi L, Pennelli N (1988) Right ventricular cardiomyopathy and sudden death in young people. N Engl J Med 318:129-33

3. Marcus FI, McKenna WJ, Sherrill D, Basso C, Bauce B, Bluemke DA, Calkins H, Corrado D, Cox MG, Daubert JP, Fontaine G, Gear K, Hauer R, Nava A, Picard MH, Protonotarios N, Saffitz JE, Sanborn DM, Steinberg JS, Tandri H, Thiene G, Towbin JA, Tsatsopoulou A, Wichter T, Zareba W (2010) Diagnosis of arrhythmogenic right ventricular cardiomyopathy/dysplasia: proposed modification of the task force criteria. Circulation 121:1533-41

4. Serri K, Reant P, Lafitte M, Berhouet M, Le Bouffos V, Roudaut R, Lafitte S. Global and regional myocardial function quantification by two-dimensional strain: application in hypertrophic cardiomyopathy (2006) J Am Coll Cardiol 47:1175-81

5. Buss SJ, Emami M, Mereles D, Korosoglou G, Kristen AV, Voss A, Schellberg D, Zugck C, Galuschky C, Giannitsis E, Hegenbart U, Ho AD, Katus HA, Schonland SO, Hardt SE (2012) Longitudinal left ventricular function for prediction of survival in systemic light-chain amyloidosis: incremental value compared with clinical and biochemical markers. J Am Coll Cardiol 60:1067-76

6. Lafitte S, Perlant M, Reant P, Serri K, Douard H, DeMaria A, Roudaut R (2009) Impact of impaired myocardial deformations on exercise tolerance and prognosis in patients with asymptomatic aortic stenosis. Eur J Echocardiogr 10:414-9 
7. Ishizu T, Seo Y, Enomoto Y, Sugimori H, Yamamoto M, Machino T, Kawamura $\mathrm{R}$, Aonuma K (2010) Experimental validation of left ventricular transmural strain gradient with echocardiographic two-dimensional speckle tracking imaging. Eur $\mathrm{J}$ Echocardiogr 11:377-85

8. Leitman M, Lysiansky M, Lysyansky P, Friedman Z, Tyomkin V, Fuchs T, Adam D, Krakover R, Vered Z (2010) Circumferential and longitudinal strain in 3 myocardial layers in normal subjects and in patients with regional left ventricular dysfunction. J Am Soc Echocardiogr 23:64-70

9. Adamu U, Schmitz F, Becker M, Kelm M, Hoffmann R (2009) Advanced speckle tracking echocardiography allowing a three-myocardial layer-specific analysis of deformation parameters. Eur J Echocardiogr 10:303-8

10. Lang RM, Bierig M, Devereux RB, Flachskampf FA, Foster E, Pellikka PA, Picard MH, Roman MJ, Seward J, Shanewise JS, Solomon SD, Spencer KT, Sutton MS, Stewart WJ (2005) Recommendations for chamber quantification: a report from the American Society of Echocardiography's Guidelines and Standards Committee and the Chamber Quantification Writing Group, developed in conjunction with the European Association of Echocardiography, a branch of the European Society of Cardiology. J Am Soc Echocardiogr 18:1440-63

11. Gottdiener JS, Bednarz J, Devereux R, Gardin J, Klein A, Manning WJ, Morehead A, Kitzman D, Oh J, Quinones M, Schiller NB, Stein JH, Weissman NJ (2004) American Society of Echocardiography. American Society of Echocardiography recommendations for use of echocardiography in clinical trials. J Am Soc Echocardiogr 17:1086-119 
12. Foale R, Nihoyannopoulos P, McKenna W, Kleinebenne A, Nadazdin A, Rowland E, Smith G (1986) Echocardiographic measurement of the normal adult right ventricle. Br Heart J 56:33-44

13. Rudski LG, Lai WW, Afilalo J, Hua L, Handschumacher MD, Chandrasekaran K, Solomon SD, Louie EK, Schiller NB (2010) Guidelines for the echocardiographic assessment of the right heart in adults: a report from the American Society of Echocardiography endorsed by the European Association of Echocardiography, a registered branch of the European Society of Cardiology, and the Canadian Society of Echocardiography. J Am Soc Echocardiogr 23:685-713

14. Leitman M, Lysyansky P, Sidenko S, Shir V, Peleg E, Binenbaum M, Kaluski E, Krakover R, Vered Z (2004) Two-dimensional strain-a novel software for real-time quantitative echocardiographic assessment of myocardial function. J Am Soc Echocardiogr 17:1021-9

15. Kramer CM, Barkhausen J, Flamm SD, Kim RJ, Nagel E (2008) Society for Cardiovascular Magnetic Resonance Board of Trustees Task Force on Standardized Protocols. Standardized cardiovascular magnetic resonance imaging (CMR) protocols, society for cardiovascular magnetic resonance: board of trustees task force on standardized protocols. J Cardiovasc Magn Reson 10:35

16.von Elm E, Altman DG, Egger M, Pocock SJ, Gøtzsche PC, Vandenbroucke JP (2007) STROBE Initiative. Strengthening the Reporting of Observational Studies in Epidemiology (STROBE) statement: guidelines for reporting observational studies. BMJ 335:806-808

17. Horimoto M, Akino M, Takenaka T, Igarashi K, Inoue H, Kawakami Y (2000) Evolution of left ventricular involvement in arrhythmogenic right ventricular cardiomyopathy. Cardiology 93:197-200 
18. Tandri H, Saranathan M, Rodriguez ER, Martinez C, Bomma C, Nasir K, Rosen B, Lima JA, Calkins H, Bluemke DA (2005) Noninvasive detection of myocardial fibrosis in arrhythmogenic right ventricular cardiomyopathy using delayedenhancement magnetic resonance imaging. J Am Coll Cardiol 45:98-103

19. Marra MP, Leoni L, Bauce B, Corbetti F, Zorzi A, Migliore F, Silvano M, Rigato I, Tona F, Tarantini G, Cacciavillani L, Basso C, Buja G, Thiene G, lliceto S, Corrado D (2012) Imaging study of ventricular scar in arrhythmogenic right ventricular cardiomyopathy: comparison of 3D standard electroanatomical voltage mapping and contrast-enhanced cardiac magnetic resonance. Circ Arrhythm Electrophysiol 5:91-100

20. Sen-Chowdhry S, Prasad SK, Syrris P, Wage R, Ward D, Merrifield R, Smith GC, Firmin DN, Pennell DJ, McKenna WJ (2006) Cardiovascular magnetic resonance in arrhythmogenic right ventricular cardiomyopathy revisited: comparison with task force criteria and genotype. J Am Coll Cardiol 48:2132-40

21. Herbots L, Kowalski M, Vanhaecke J, Hatle L, Sutherland GR (2003) Characterizing abnormal regional longitudinal function in arrhythmogenic right ventricular dysplasia. The potential clinical role of ultrasonic myocardial deformation imaging. Eur J Echocardiogr 4:101-7

22. Vitarelli A, Cortes Morichetti M, Capotosto L, De Cicco V, Ricci S, Caranci F, Vitarelli M (2013) Utility of strain echocardiography at rest and after stress testing in arrhythmogenic right ventricular dysplasia. Am J Cardiol 111:1344-50

23. Teske AJ, Cox MG, De Boeck BW, Doevendans PA, Hauer RN, Cramer MJ (2009) Echocardiographic tissue deformation imaging quantifies abnormal regional right ventricular function in arrhythmogenic right ventricular dysplasia/cardiomyopathy. J Am Soc Echocardiogr 22:920-7 
24. Teske AJ, Cox MG, Te Riele AS, De Boeck BW, Doevendans PA, Hauer RN, Cramer MJ (2012) Early detection of regional functional abnormalities in asymptomatic ARVD/C gene carriers. J Am Soc Echocardiogr 25:997-1006

25. Lang RM, Badano LP, Mor-Avi V, Afilalo J, Armstrong A, Ernande L, Flachskampf FA, Foster E, Goldstein SA, Kuznetsova T, Lancellotti P, Muraru D, Picard MH, Rietzschel ER, Rudski L, Spencer KT, Tsang W, Voigt JU (2015) Recommendations for cardiac chamber quantification by echocardiography in adults: an update from the American Society of Echocardiography and the European Association of Cardiovascular Imaging. Eur Heart $\mathrm{J}$ Cardiovasc Imaging 16:233-70

26. Peyrou J, Parsaï C, Chauvel C, Simon M, Dehant P, Abergel E (2014) Echocardiographic assessment of right ventricular systolic function in a population of unselected patients before cardiac surgery: a multiparametric approach is necessary. Arch Cardiovasc Dis 107:529-39

27. Aneq MÅ, Engvall J, Brudin L, Nylander E (2012) Evaluation of right and left ventricular function using speckle tracking echocardiography in patients with arrhythmogenic right ventricular cardiomyopathy and their first degree relatives. Cardiovasc Ultrasound 10:37

28. Risum N, Ali S, Olsen NT, Jons C, Khouri MG, Lauridsen TK, Samad Z, Velazquez EJ, Sogaard P, Kisslo J (2012) Variability of global left ventricular deformation analysis using vendor dependent and independent two-dimensional speckle tracking software in adults. J Am Soc Echocardiogr 25:1195-2003 


\section{Figures Legend}

Figure 1: Transmural LV LS in group II vs. controls: regional analysis; significant alteration of LS in the basal infero-septal, mid infero-septal, septo-apical, latero-apical, basal infero-lateral, mid antero-lateral, and basal antero-lateral segments (total $=7$ segments, pink color). Values are expressed in \%.

Figure 2: Endocardial LV LS in group II vs. controls: regional analysis; significant alteration of LS in the basal infero-septal, mid infero-septal, septo-apical, basal infero-lateral, and mid antero-lateral segments (total $=5$ segments, pink color). Values are expressed in \%.

Figure 3: Epicardial LV LS in group II vs. controls: regional analysis; significant alteration of LS in the basal infero-septal, mid infero-septal, septo-apical, lateroapical, basal infero-lateral, mid antero-lateral, and basal antero-lateral segments (total $=7$ segments, pink color). Values are expressed in \%.

Figure 4: Receiver operating characteristics curve analysis of regional LS analysis to predict presence of LGE. 
Table 1: Baseline clinical, demographic and main echocardiographic characteristics of the population

\begin{tabular}{|c|c|c|c|c|c|c|}
\hline Parameters & $\begin{array}{l}\text { Group IV } \\
(\mathrm{N}=70)\end{array}$ & $\begin{array}{l}\text { Group III } \\
(\mathrm{N}=19)\end{array}$ & $\begin{array}{l}\text { Group II } \\
(\mathrm{N}=27)\end{array}$ & $\begin{array}{l}\text { Group I } \\
(\mathrm{N}=26)\end{array}$ & $\begin{array}{c}p \text { value } \\
\text { group I } \\
\text { vs II }\end{array}$ & $\begin{array}{c}p \text { value } \\
\text { Anova }\end{array}$ \\
\hline Male gender-no. (\%) & $35(49)$ & $10(53)$ & $10(37)$ & $10(38)$ & 0.91 & 0.59 \\
\hline Age (years) & $46.6 \pm 14.2$ & $44.8 \pm 18.7$ & $39.6 \pm 19.5$ & $38.7 \pm 11.4$ & 0.83 & 0.071 \\
\hline Body surface area $\left(\mathrm{m}^{2}\right)$ & $1.9 \pm 0.2$ & $1.9 \pm 0.2$ & $1.8 \pm 0.2$ & $1.7 \pm 0.2$ & 0.07 & $<0.001$ \\
\hline Heart rate (beats/min) & $60.6 \pm 12.0$ & $65.4 \pm 15.7$ & $69.9 \pm 11.9$ & $67.5 \pm 12.1$ & 0.47 & 0.005 \\
\hline \multicolumn{7}{|l|}{ Left heart variables } \\
\hline Septal WT (mm) & $7.8 \pm 1.3$ & $7.6 \pm 1.3$ & $7.4 \pm 1.2$ & $7.6 \pm 1.5$ & 0.66 & 0.51 \\
\hline LV ED volume $\left(\mathrm{ml} / \mathrm{m}^{2}\right)$ & $55.5 \pm 13.6$ & $56.7 \pm 11.9$ & $52.8 \pm 13.3$ & $56.8 \pm 14.6$ & 0.35 & 0.75 \\
\hline LV ES volume $\left(\mathrm{ml} / \mathrm{m}^{2}\right)$ & $20.4 \pm 7.1$ & $18.0 \pm 4.5$ & $17.2 \pm 5.1$ & $18.4 \pm 5.7$ & 0.44 & 0.13 \\
\hline LV fractional shortening (\%) & $34.1 \pm 5.3$ & $37.8 \pm 4.7$ & $34.9 \pm 4.4$ & $37.5 \pm 5.6$ & 0.055 & 0.004 \\
\hline LV EF (\%) & $64.6 \pm 6.9^{\star}$ & $67.6 \pm 5.6$ & $68.0 \pm 5.2$ & $67.2 \pm 4.0$ & 0.55 & 0.030 \\
\hline GLS (\%) & $17.1 \pm 3.1$ & $19.3 \pm 2.9$ & $19.3 \pm 1.9$ & $20.9 \pm 1.1$ & 0.0003 & $<0.001$ \\
\hline S' LV lateral (cm/s) & $8.0 \pm 2.5$ & $9.8 \pm 1.9$ & $11.1 \pm 2.6$ & $10.6 \pm 2.5$ & 0.48 & $<0.001$ \\
\hline E peak (cm/s) & $71.3 \pm 18.5$ & $67.9 \pm 12.8$ & $76.3 \pm 16.9$ & $82.2 \pm 13.6$ & 0.17 & 0.013 \\
\hline E/E' ratio & $6.8 \pm 2.9$ & $5.9 \pm 1.8$ & $5.8 \pm 1.5$ & $5.5 \pm 1.5$ & 0.43 & 0.064 \\
\hline LA volume index $\left(\mathrm{ml} / \mathrm{m}^{2}\right)$ & $26.2 \pm 8.3$ & $27.5 \pm 6.8$ & $23.3 \pm 8.6$ & $23.5 \pm 6.4$ & 0.94 & 0.18 \\
\hline \multicolumn{7}{|l|}{ Right heart variables } \\
\hline Minor RV echo criteria-no. & $2(3)$ & $0(0)$ & $0(0)$ & $0(0)$ & & \\
\hline Major RV echo criteria-no. & $34(49)$ & $0(0)$ & $0(0)$ & $0(0)$ & & \\
\hline RV ED area $\left(\mathrm{cm}^{2} / \mathrm{m}^{2}\right)$ & $13.3 \pm 4.3$ & $10.1 \pm 1.8$ & $9.9 \pm 2.0$ & $10.0 \pm 1.7$ & 0.86 & $<0.001$ \\
\hline RV FAC (\%) & $39.9 \pm 10.5$ & $45.2 \pm 7.1$ & $51.7 \pm 8.5$ & $50.3 \pm 6.5$ & 0.28 & $<0.001$ \\
\hline RVOT diameter $\left(\mathrm{mm} / \mathrm{m}^{2}\right)$ & $18.5 \pm 3.4$ & $16.0 \pm 2.3$ & $16.5 \pm 2.1$ & $17.1 \pm 2.4$ & 0.39 & 0.002 \\
\hline TAPSE (mm) & $20.3 \pm 4.9$ & $22.8 \pm 3.4$ & $21.6 \pm 3.5$ & $24.2 \pm 2.8$ & 0.004 & 0.001 \\
\hline RV S' TDI (cm/s) & $10.2 \pm 2.7$ & $12.2 \pm 1.6$ & $13.2 \pm 1.8$ & $15.0 \pm 2.1$ & 0.009 & $<0.001$ \\
\hline PASP (mmHg) & $24.0 \pm 4.7$ & $24.8 \pm 6.5$ & $23.4 \pm 4.4$ & $22.3 \pm 2.7$ & 0.29 & 0.31 \\
\hline Global RV strain (\%) & $20.9 \pm 7.2$ & $29.0 \pm 4.4$ & $26.8 \pm 5.1$ & $31.0 \pm 4.2$ & 0.005 & $<0.001$ \\
\hline
\end{tabular}

$\mathrm{WT}=$ wall thickness, $\mathrm{LV}=$ left ventricular, ED = end-diastolic, ES $=$ end-systolic, $E F=$ ejection fraction, GLS = global longitudinal strain, $L A=$ left atrial, $R V=$ right ventrcular, $F A C$ $=$ fractional area change, RVOT $=$ RV outflow tract, TAPSE $=$ tricuspid antero-posterior systolic excursion, TDI = tissue Doppler imaging, PASP = pulmonary artery systolic pressure.

${ }^{*} \mathrm{n}=4$ patients with LVEF $<55 \%$ 
Table 2: Multilayers LV GLS and RV regional strain analyses

\begin{tabular}{lcccccc}
\hline Parameters & $\begin{array}{c}\text { Group IV } \\
(\mathrm{N}=70)\end{array}$ & $\begin{array}{c}\text { Group III } \\
(\mathrm{N}=19)\end{array}$ & $\begin{array}{c}\text { Group II } \\
(\mathrm{N}=27)\end{array}$ & $\begin{array}{c}\text { Group I } \\
(\mathrm{N}=26)\end{array}$ & $\begin{array}{c}p \text { value } \\
\text { group II } \\
\text { vs I }\end{array}$ & $\begin{array}{c}p \text { value } \\
\text { Anova }\end{array}$ \\
\hline LV & & & & & & \\
Transmural LV GLS (\%) & $17.1 \pm 3.1$ & $19.1 \pm 2.8$ & $19.3 \pm 1.8$ & $20.9 \pm 1.1$ & $<\mathbf{0 . 0 0 1}$ & $<\mathbf{0 . 0 0 1}$ \\
Endo LV GLS (\%) & $19.7 \pm 3.6$ & $22.3 \pm 3.5$ & $22.3 \pm 2.0$ & $24.3 \pm 1.3$ & $<0.001$ & $<0.001$ \\
Epi LV GLS (\%) & $14.8 \pm 2.8$ & $16.7 \pm 2.4$ & $16.9 \pm 1.8$ & $18.4 \pm 1.1$ & $<0.001$ & $<\mathbf{0 . 0 0 1}$ \\
RV & & & & & & \\
Basal RV LS (\%) & $21.1 \pm 9.0$ & $29.6 \pm 5.9$ & $29.6 \pm 6.4$ & $30.8 \pm 6.0$ & 0.54 & $<\mathbf{0 . 0 0 1}$ \\
Mid RV LS (\%) & $21.6 \pm 9.0$ & $30.7 \pm 5.1$ & $28.3 \pm 6.0$ & $32.2 \pm 4.4$ & $\mathbf{0 . 0 2 0}$ & $<\mathbf{0 . 0 0 1}$ \\
Apical RV (\%) & $19.5 \pm 6.6$ & $26.0 \pm 4.7$ & $20.8 \pm 5.7$ & $29.9 \pm 4.7$ & $<0.001$ & $<\mathbf{0 . 0 0 1}$ \\
\hline
\end{tabular}

Endo $=$ endocardial, Epi $=$ epicardial, $L V=$ left ventricular, GLS = global longitudinal strain, $\mathrm{RV}=$ right ventricular, $\mathrm{LS}=$ longitudinal strain 
Table 3: Intra- and interobserver mean percentage variability of LS analysis

\begin{tabular}{lcccccc}
\hline $\begin{array}{l}\text { Mean variability } \\
\text { LV strain }\end{array}$ & $\begin{array}{c}\text { GLS } \\
\text { transmural }\end{array}$ & $\begin{array}{c}\text { GLS } \\
\text { Endo }\end{array}$ & $\begin{array}{c}\text { GLS } \\
\text { Epi }\end{array}$ & $\begin{array}{c}\text { Regional LS } \\
\text { transmural }\end{array}$ & $\begin{array}{c}\text { Regional } \\
\text { LS Endo }\end{array}$ & $\begin{array}{c}\text { Regional } \\
\text { LS Epi }\end{array}$ \\
\hline Intraobserver & $3.4 \%$ & $3.1 \%$ & $4.6 \%$ & $8.2 \%$ & $7.8 \%$ & $8.9 \%$ \\
Interobserver & $4.2 \%$ & $3.7 \%$ & $6.1 \%$ & $12.2 \%$ & $12.8 \%$ & $13.0 \%$ \\
\hline \multicolumn{1}{l}{} & & & & & & \\
\hline Mean variability & GLS & GLS & GLS & Regional LS & Regional & Regional \\
RV strain & transmural & Endo & Epi & transmural & LS Endo & LS Epi \\
\hline Intraobserver & $8.3 \%$ & $6.1 \%$ & $9.8 \%$ & $9.0 \%$ & $7.7 \%$ & $11.5 \%$ \\
Interobserver & $11.8 \%$ & $10.8 \%$ & $11.9 \%$ & $10.2 \%$ & $9.7 \%$ & $11.1 \%$ \\
\hline
\end{tabular}

$L V=l$ eft ventricular, GLS=global longitudinal strain, Endo=endocardial, Epi=epicardial, $\mathrm{LS}=$ longitudinal strain, $\mathrm{RV}=$ right ventricular. 


\section{Figure 1}

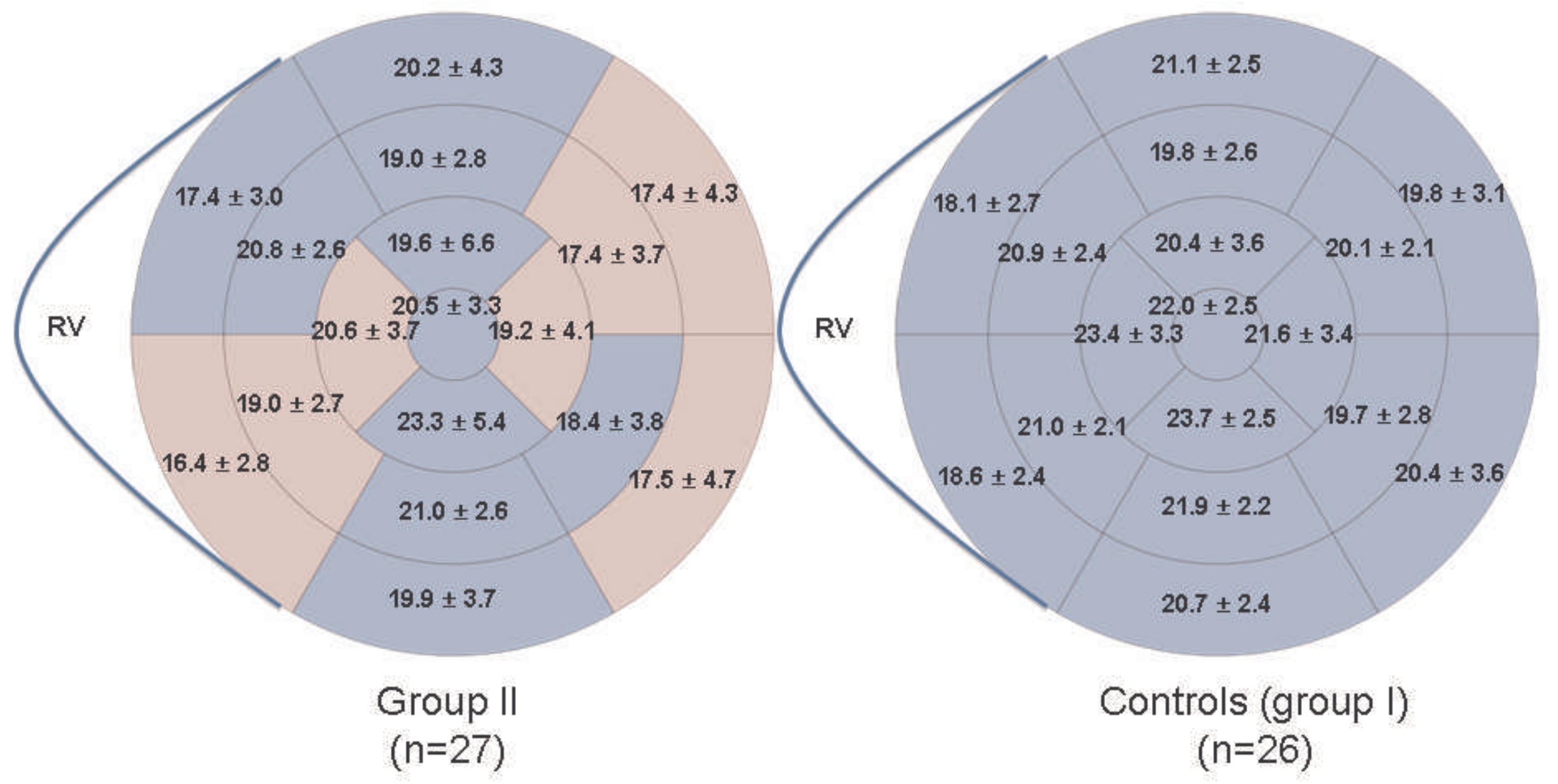

$p \leq 0.05$ between group II and controls (group I) 


\section{Figure 2}

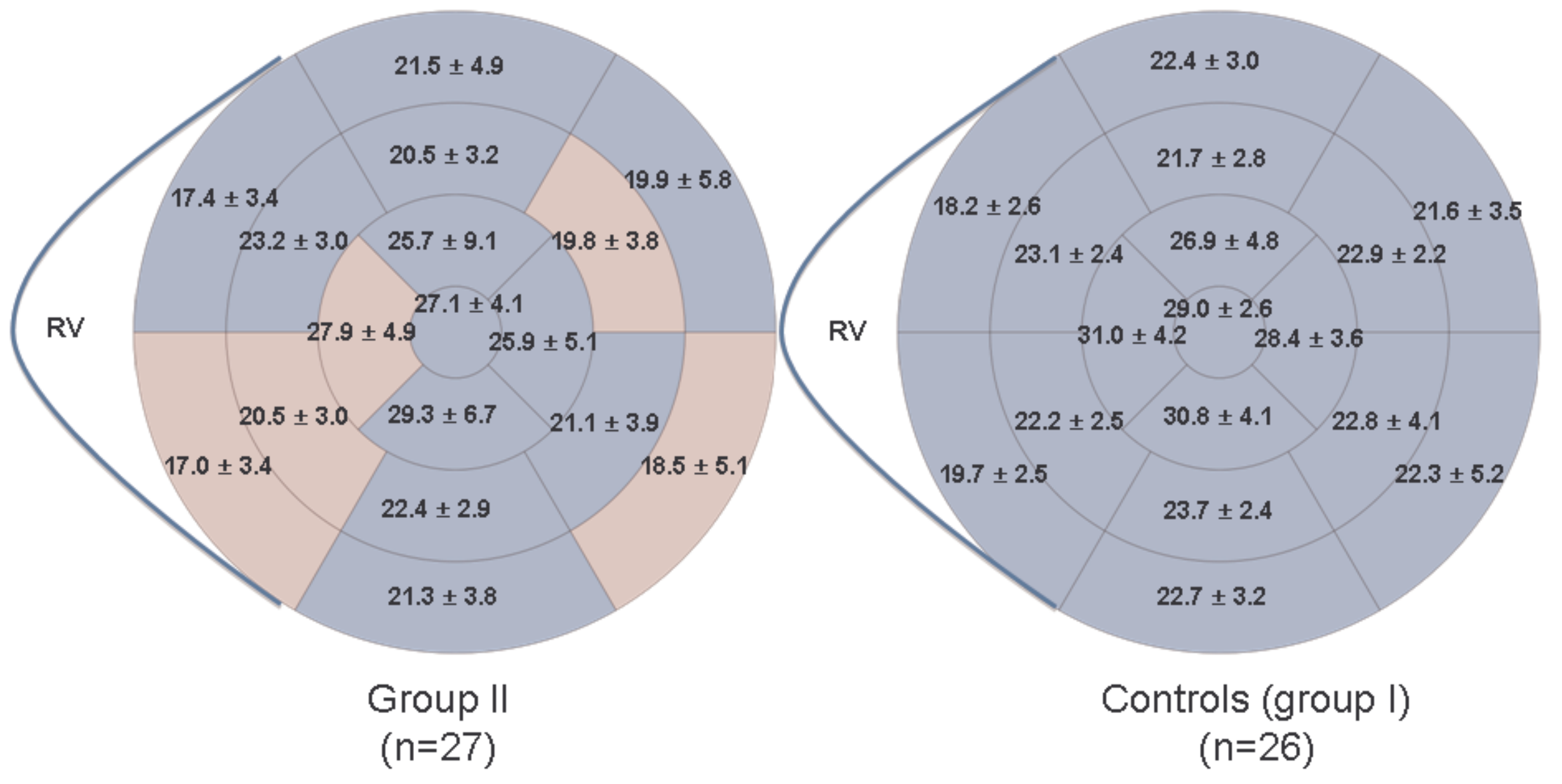

p $\leq 0.05$ between group II and controls (group I) 


\section{Figure 3}

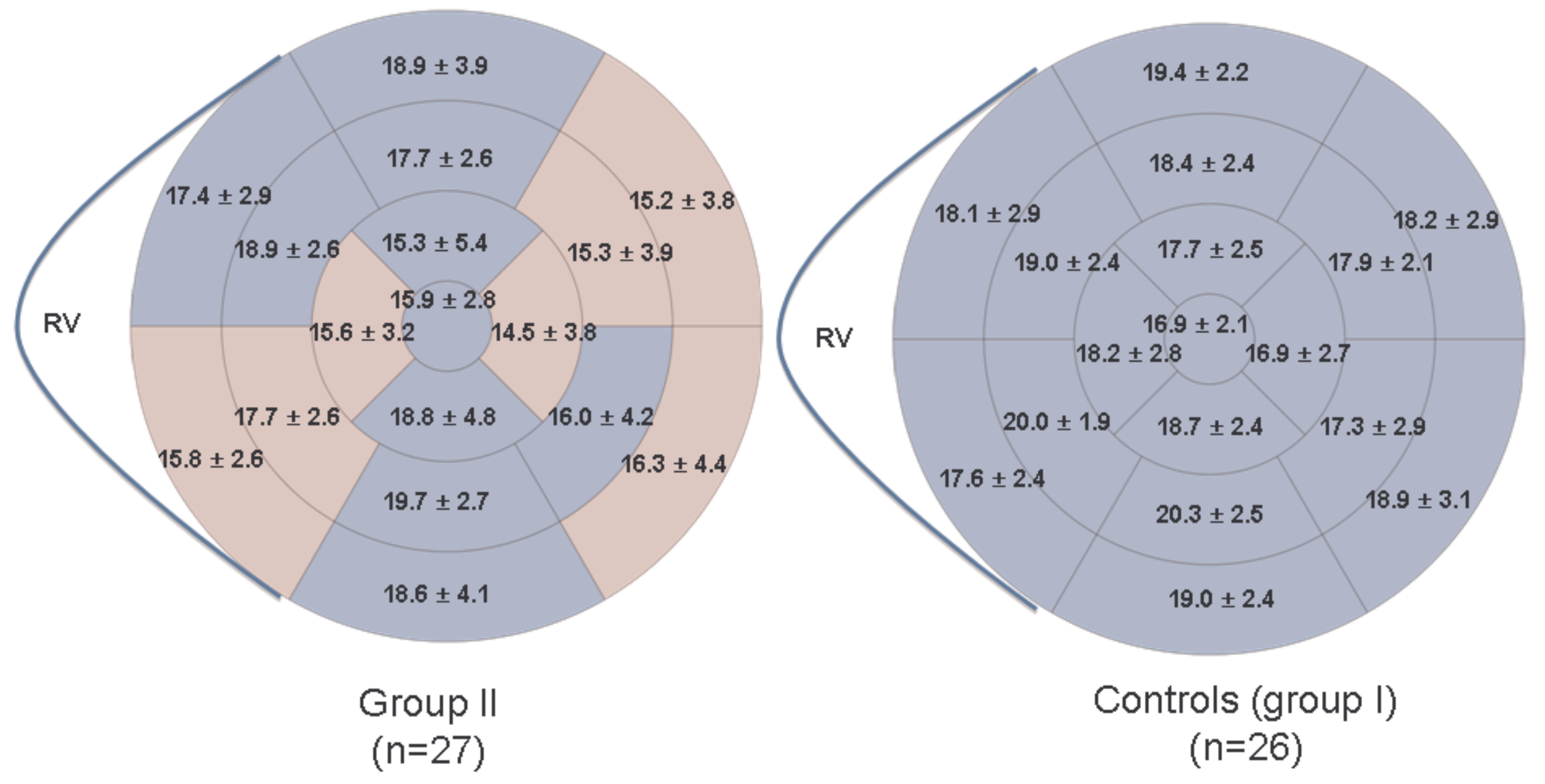

p $\leq 0.05$ between group II and controls (group I) 
Figure 4

\section{ROC Curve}

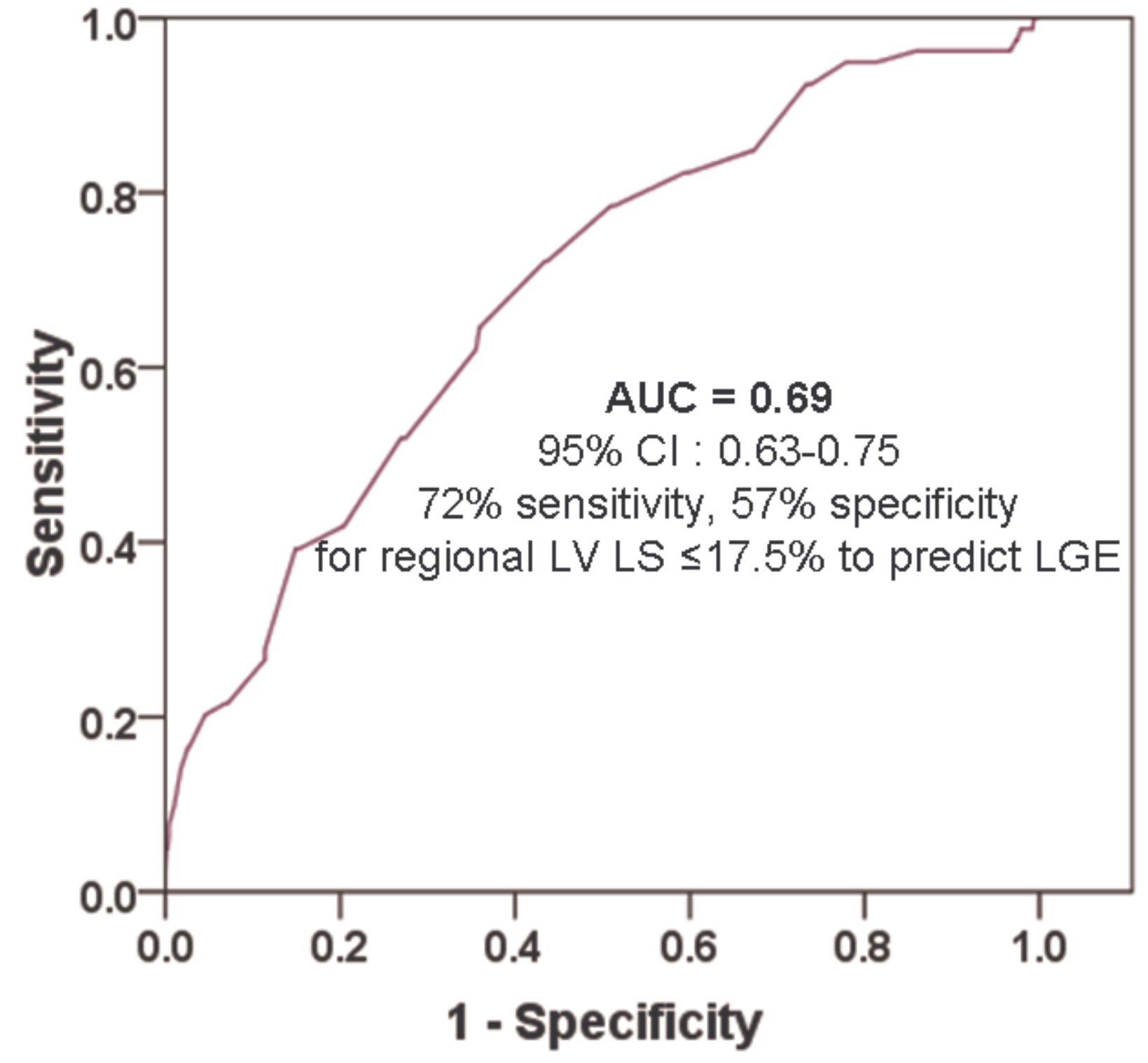

